Check for updates

Cite this: RSC Adv., 2017, 7, 18529

Received 8th November 2016

Accepted 21st March 2017

DOI: 10.1039/c6ra26514f

rsc.li/rsc-advances

\section{Microwave energy assisted synthesis of poly lactic acid via continuous reactive extrusion: modelling of reaction kinetics}

\author{
Satya P. Dubey, (D) ${ }^{a}$ Hrushikesh A. Abhyankar, ${ }^{* a}$ Veronica Marchante, ${ }^{a}$ \\ James L. Brighton, ${ }^{a}$ Björn Bergmann, ${ }^{\text {b Giang } \text { Trinh }^{c} \text { and Chantal David }}{ }^{c}$
}

The most commonly used batch process to manufacture PLA is ring opening polymerization (ROP) of lactide monomer in a suitable solvent, in the presence of a metallic/bimetallic catalyst (Sn, Zn, and Al) or other organic catalysts. However, this process does not lend itself to safer/cleaner and high throughput (and high volume) manufacturing. Continuous reactive extrusion of lactide monomer using a suitable reaction input has the potential to increase the throughput, and this route has been explored in the literature. In this work, reactive extrusion experiments using stannous octoate $\mathrm{Sn}(\mathrm{Oct})_{2}$ and tri-phenyl phosphine $(\mathrm{PPh})_{3}$, were considered to perform ROP of lactide monomer using the microwave as an alternative energy (AE) source for activating and/or boosting the polymerization. Implementation of a microwave generator in a section of the extruder is one of the novelties of this research. A simulation model of ROP of PLA was formulated to estimate the impact of reaction kinetics and AE source on the polymerization process. Ludovic ${ }^{\circledR}$ software was used for the simulation of continuous reactive extrusion of the process. Experimental and simulated results were compared for the validation of the methodology. This work also highlights the advantages and drawbacks of most conventional metal catalysts, the effect of alternative energies on reaction mechanism, and safe and efficient production of PLA.

\section{Introduction}

The production of waste, especially from consumable products, is one of the major challenges of the present era. Polymers represent $20-30 \%$ of global waste, ${ }^{1,2}$ leading to problems such as decomposition and recycling of the polymers. As alternatives, bio-mass and/or bio-degradable polymers such as cellulose acetate (CA), poly-butylene succinate (PBS), poly-lactic acid (PLA), poly-urethane (PU) etc. have gained interest. Among these bio-plastics, poly-lactide or poly lactic acid (PLA) has been gaining interest in the past few decades..$^{2-5}$

For decades, the conventional commercial method for synthesis of PLA was ring-opening polymerisation (ROP) based on metal (Sn, Al, Zn) catalysis of lactide using suitable cocatalyst such as dodecanol in a suitable solvent (toluene). ${ }^{1,6-11}$ However, PLA produced using the conventional methods may contain traces of the metal catalysts, restricting the potential applications for the final product. ${ }^{6}$

\footnotetext{
${ }^{a}$ Advanced Vehicle Engineering Centre (AVEC), School of Aerospace, Transport and Manufacturing (SATM), Cranfield University, MK43 OAL Cranfield, UK. E-mail: s.p. dubey@cranfield.ac.uk; h.a.abhyankar@cranfield.ac.uk

${ }^{b}$ Polymer Engineering, Fraunhofer-ICT, Joseph-von-Fraunhofer-Straße 7, 76327 Pfinztal, Germany

${ }^{c}$ Sciences Computers Consultants (SCC), 10 Rue du Plateau des Glières, 42000 SaintÉtienne, France
}

Several attempts were made to substitute tin-based catalysts by catalysts that exhibit less toxicity or eco-toxicity. ${ }^{8-16}$ Typically, the alternative catalysts require a higher amount of energy of activation. ${ }^{17}$ Initial experimental trials support the use of alternative energy sources (LASER, Ultrasounds, microwaves) to facilitate the ROP of lactide monomers. ${ }^{18-27}$

Several projects and research groups are trying to optimize the polymerization of PLA through cleaner, efficient and safer processes. ${ }^{15,26-28}$ One such project is InnoREX. ${ }^{28}$ The main aim of this project was to combine eco-friendly catalysis with reactive extrusion (REX) for ROP of lactide to obtain a high throughput. ${ }^{29,30,32}$ The project also explored the use of alternative energy sources (microwave, ultrasound) to reduce the total energy consumption and further increase the eco-friendly credentials. Application of microwave heating to chemical reactions has received a lot of attention in the past few years. ${ }^{15}$ Due to its qualities such as high efficiency, the capability of uniform heating and reduced reaction time, a large number of chemical reactions undergo a significant increase in reaction speed due to microwave irradiation compared to the general methods for heat-irradiation such as furnace chamber and LASER heating etc. ${ }^{17-20}$ Liu et al. ${ }^{19}$ and Cheng et al.$^{20}$ investigated the microwave-assisted radical polymerization of styrene with a faster polymerization rate in comparison to conventional heating. Some studies were also conducted to produce PLA. The first microwave-irradiated polymerization of D,L-lactide to 
support the reaction process for higher output was reported by Albert et al. and Liu et al. AE source was used as source of heating to provide a suitable energy for polymerization process. ${ }^{18,19,33}$

Based on several reactive extrusion experiments results from Dubey et al., Banu et al. ${ }^{\mathbf{2 9 , 3 0 , 3 4 , 3 5}}$ concluded that the combination of microwave heating technology and living free radical polymerization (LRP), can increase the rate and effectiveness of reactions. ${ }^{25}$ It must, however, be added that although there are studies that use $\mathrm{AE}$ in reactive extrusion, to the best of the author's knowledge, there is there is no comprehensive study in the area of modelling ROP of lactide process mechanism when $\mathrm{AE}$ in the form of microwave energy is used.

In this work, the impact of $\mathrm{AE}$ on ROP of LA using metal catalyst was investigated through reactive extrusion experiments and validated by modelling the reactive extrusion using Ludovic ${ }^{\circledR}$ software. ${ }^{32}$ The reported study can be divided into three different stages Fig. 1. (1) Extrusion experiments - to obtain experimental data of ROP of LA using stannous octoate $\left(\mathrm{Sn}(\mathrm{Oct})_{2}\right)$ as catalyst and applying microwave; (2) simulation of batch process, using initial parameters of extrusion experiment (Dubey et al..$^{29,30}$, to obtain isothermal curves; and (3) implementation of the isothermal curves (output of step 2) in Ludovic ${ }^{\circledR}$ software $^{32}$ to simulate reactive extrusion process of PLA formation.

\section{Materials and processes}

\subsection{Materials details}

The monomer used for the reactive extrusion was L-lactide (Sigma-Aldrich), the catalyst, co-catalyst and initiator were stannous octoate $\left(\mathrm{Sn}(\mathrm{Oct})_{2}\right)$ (Sn-bis(2-ethylhexanoate), SigmaAldrich), triphenylphosphine (PPh) ${ }_{3}$ (Sigma-Aldrich), and 1dodecanol (Sigma-Aldrich), respectively.

2.1.1. Experimental process: reactive extrusion of PLA. Reactive extrusion experiments were performed at Fraunhofer, ICT laboratory, ${ }^{31}$ using Leistritz $27 \mathrm{HP}$, a co-rotating twin screw extruder. The configuration of the twin screw extruder are as follows: $18 \mathrm{~mm}$ diameter barrel and length/diameter ratio $(L /$

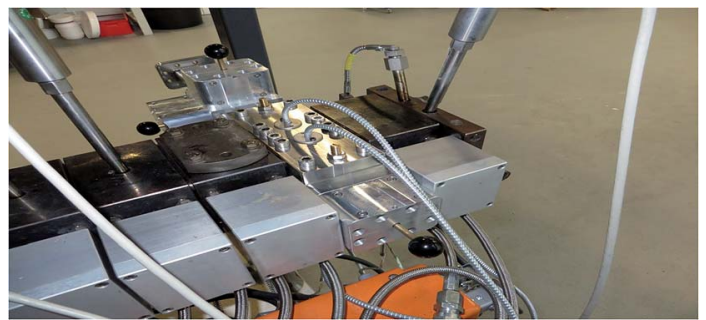

Fig. 2 Microwave incorporation block to the twin-screw extruder MUEGGE®.

$D)=52$, temperature range $(160-200){ }^{\circ} \mathrm{C}$. Microwave energy was applied in this process using a 'Microwave Device' (MUEGGE, Germany $^{26}$ ) for 3-15 minutes. Microwave source range ( $0.5 \mathrm{GHz}$ min to $5.8 \mathrm{GHz}$ max) was implemented. For this particular research work industrially relevant frequencies of $2.45 \mathrm{GHz}$ were implemented for heating the material in the reaction process. An extruder window block was specifically designed to facilitate the application of microwave. Based on several trials for microwave device position, the device was mounted in this block at a distance of $25 \mathrm{D}$ from the feeding zone. See Fig. 2.

For the reaction, monomer and catalysts were pre-mixed under inert gas atmosphere to avoid moisture impurities and fed into main feed. The initial concentration of the reactants and some initial conditions of the experiments are shown in Table 1.

\subsection{Characterisation techniques}

Monomer conversion $(X)$ and average molecular weight $\left(\overline{M_{\mathrm{n}}}\right)$ were measured at several temperatures, time and molecular monomer to initiator ratios. Then, samples were taken at different stages of the reaction process to evaluate the polymerization efficiency.

2.2.1. Gel permeation chromatography (GPC). Gel Permeation Chromatography (GPC) device [Polymer Standards Service $\mathrm{GmbH}$ (PSS), USA] was equipped as follows:

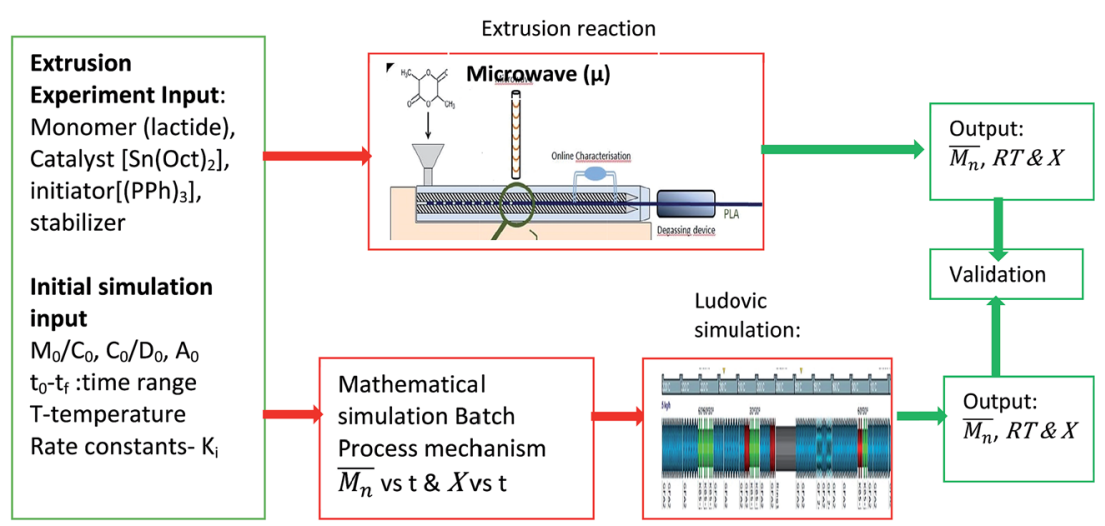

Fig. 1 Schematic to explain reaction parameters. $M_{0}$ : initial concentration of monomer, $C_{0}$ : initial concentration of catalyst $S n(O c t){ }_{2}$, $D_{0}$ : initial concentration of $\mathrm{OH}$ group source, $A_{0}$ : initial concentration of octanoic acid $(\mathrm{OctOH}),\left(\overline{M_{\mathrm{n}}}\right)$ number average molecular weight, $X$ : conversion, $\mathrm{RT}$ : residential time, $K_{\mathrm{i}}$ : rate constants. 
Table 1 Twin-screw extrusion reaction parameters

\begin{tabular}{lll}
\hline Symbol & Parameter & Value (unit) \\
\hline$M_{0}$ & Initial concentration of monomer & $8.3 \mathrm{~mol} \mathrm{~L}^{-1}$ \\
$C_{0}$ & Initial concentration of catalyst & $0.008 \mathrm{~mol} \mathrm{~L}^{-1}$ \\
$D_{0}$ & Initial concentration of co-catalyst & $0.008 \mathrm{~mol} \mathrm{~L}^{-1}$ \\
$T_{0}$ & Initial feeding temperature & $30{ }^{\circ} \mathrm{C}$ \\
$M$ & Monomer mass flow & $0.5-2.0 \mathrm{~m} \mathrm{~kg}^{-1}$ \\
$\mathrm{rpm}$ & Rotational speed & 40 to $1000 \mathrm{rpm}$
\end{tabular}

- Poly(styrene sulfonate) (PSS) (series 1100, Agilent), at $35^{\circ} \mathrm{C}$;

- Columns: [PSS PFG $7 \mu \mathrm{m} 8 \times 50 \mathrm{~mm}$ (guard column) PSS PFG $7 \mu \mathrm{m} 8 \times 300 \mathrm{~mm} ; 100$ A PSS PFG $7 \mu \mathrm{m} 8 \times 300 \mathrm{~mm}$; $1000 \mathrm{~A}]$;

- Flow: 1, $0 \mathrm{~mL} \min ^{-1}$;

- Refractive Index Detector Agilent 1100;

- Injection volume: $100 \mu \mathrm{L}$;

- Hexafluoroisopropanol (HFIP) as a solvent;

Calibration was based on solutions of poly(methylmethacrylate) (PMMA), the values were not absolute, but relative to the standard used.

2.2.2. Proton nuclear magnetic resonance ( $\left.{ }^{1} \mathrm{H}-\mathrm{NMR}\right)$. Proton nuclear magnetic resonance analysis was conducted in $\mathrm{CDCl}_{3}$ using a Bruker (250) $\mathrm{MHz}$ spectrometer (Coventry, UK) at $30{ }^{\circ} \mathrm{C}$. The solution concentration used was $5 \mathrm{w} / \mathrm{v} \%$. This technique was applied to determine the monomer concentration and from that the conversion rate $(X)$. This analysis was also applied to the sample collected from the extruder, which was a mixture of monomer and polymer. Several numbers of scans (100) were performed for each sample.

\section{Mathematical modelling of reactive extrusion}

Developing the simulation model which defines the extrusion process was divided into two parts: firstly the development of a mathematical model describing the rate kinetics of ROP reaction in the batch process, and secondly integrating this model into Ludovic ${ }^{\circledR}$ software. From the ROP model for the batch process, isothermal curves for the evolution of number average molecular weight $\left(\overline{M_{\mathrm{n}}}\right)$ and conversion $(X)$ with time were obtained. These curves were discretised and integrated (table input) in Ludovic ${ }^{\circledR}$. This way, Ludovic ${ }^{\circledR}$ was developed and described in detail by Dubey et al. ${ }^{33}$

\subsection{Reaction kinetics modelling and mathematical simulation of ROP of lactide}

The reaction mechanisms of ROP of PLA were studied and the mathematical modelling using $\mathrm{Sn}(\mathrm{Oct})_{2}$ as catalyst was developed and described in detail was reported by Dubey et al. ${ }^{\mathbf{2 9 , 3 0}}$ The model covered the details of mathematical modelling of polymerization of lactide, based on five stages of the reaction mechanism, that is initiation, propagation, termination (intermolecular mainly), trans-esterification and non-radical random chain scission.
Table 2 Initial reaction parameters for simulation

\begin{tabular}{lll}
\hline Symbol & Parameter & Value (unit) \\
\hline$M_{0}$ & Initial concentration of monomer & $8.326 \mathrm{~mol} \mathrm{~L}^{-1}$ \\
$C_{0}$ & Initial concentration of catalyst & $0.008 \mathrm{~mol} \mathrm{~L}^{-1}$ \\
$D_{0}$ & Initial concentration of co-catalyst & $0.008 \mathrm{~mol} \mathrm{~L}^{-1}$ \\
$T_{0}$ & Initial temperature & $30{ }^{\circ} \mathrm{C}$ \\
$A_{0}$ & Octanoic acid (OctOH) & $0.24 \mathrm{~mol} \mathrm{~L}^{-1}$ \\
$M_{\mathrm{e}}$ & Monomer equilibrium concentration & $0.225 \mathrm{~mol} \mathrm{~L}^{-1}$
\end{tabular}

The kinetic parameters involved in the reaction mechanism such as several rate constants ( $k$ values) $k_{\mathrm{p}}, k_{\mathrm{d}}$ and monomer at the equilibrium concentration $\left(M_{\mathrm{e}}=k_{\mathrm{p}} / k_{\mathrm{d}}\right)$ etc. were taken straight from the literature. ${ }^{30}$ Dubey et al. ${ }^{29,30,33}$ covers mostly the details of research work related to mathematical modelling of ROP process of lactide in last 10 years or so. This mathematical model provided the isothermal curves that were implemented in Ludovic $\AA$. For the generation of the isothermal curves, the initial reaction inputs (Table 2) were selected according to the experiments on reactive extrusion conducted by Fraunhofer ICT.

The isothermal curves, conversion $(X)$ and number average molecular weight $\left(\overline{M_{\mathrm{n}}}\right)$ with time, for the total reaction time of $30 \mathrm{~min}(0.50 \mathrm{~h})$ and temperature range of $(160-230){ }^{\circ} \mathrm{C}$ were

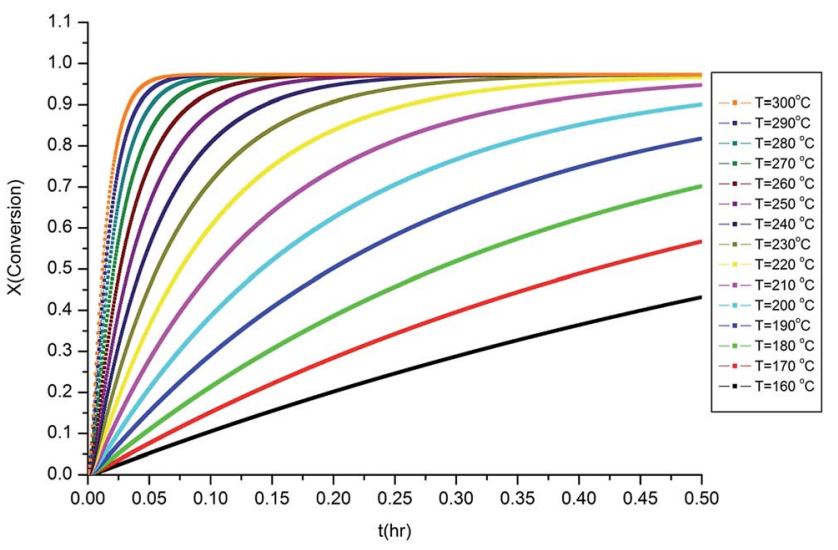

Fig. 3 Isothermal curves for conversion $(X)$ vs. $t$.

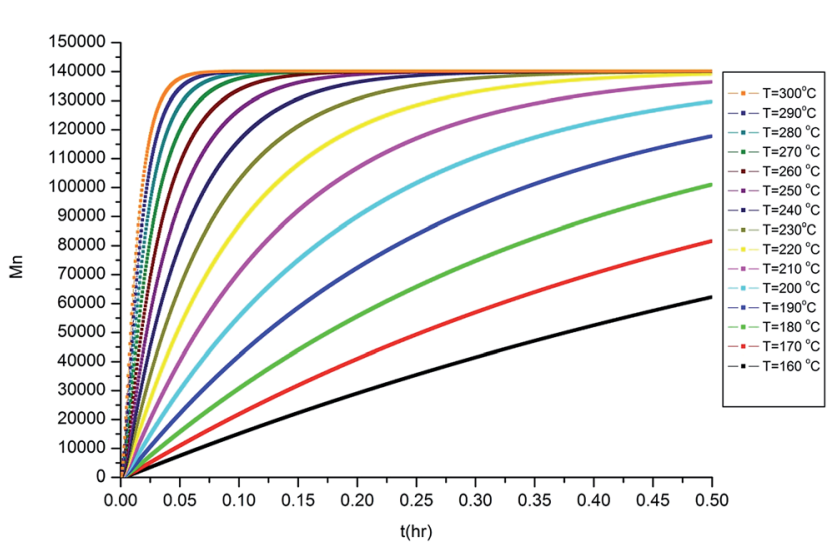

Fig. 4 Isothermal curves for average molecular weight $\left(\overline{M_{n}}\right)$ vs. $t$. 
developed to facilitate input for Ludovic $₫$. The duration of the input data was based on the residence time reported by experiments on reactive extrusion of PLA. Details of the input data are shown in Fig. 3 and 4.

\subsection{Modelling of ROP reaction mechanism in reactive extrusion}

Ludovic $®$ is one of the most used software's for the simulation of extrusion processes. ${ }^{31-33}$ At present, commercial versions of this software do not come with an option to simulate reactive extrusion, i.e. when a reaction happens during the extrusion process (within the extruder barrel). In order to adapt the software for accurate simulation of ROP of PLA, it was necessary to introduce the effect of the reactions happening within the extruder barrel on the properties of the system i.e. variation of the concentrations of initiator, monomer, polymer and their varying percentages as the reaction progresses, variation of parameters like temperature, pressure, etc.

Ludovic ${ }^{\circledR}$ software works by breaking down the extrusion process (along the barrel) into small subsections (nodes). Then, Ludovic ${ }^{\circledR}$ performs an iterative process (this is explained in the next section) to calculate all the parameters from the die to the hopper. With the implementation of the isothermal curves (molecular weight vs. time, viscosity vs. time, shear rate $v s$. time, etc.) it is possible to use Ludovic ${ }^{\circledR}$ to estimate the effect of the reaction into the extrusion parameters and to predict the

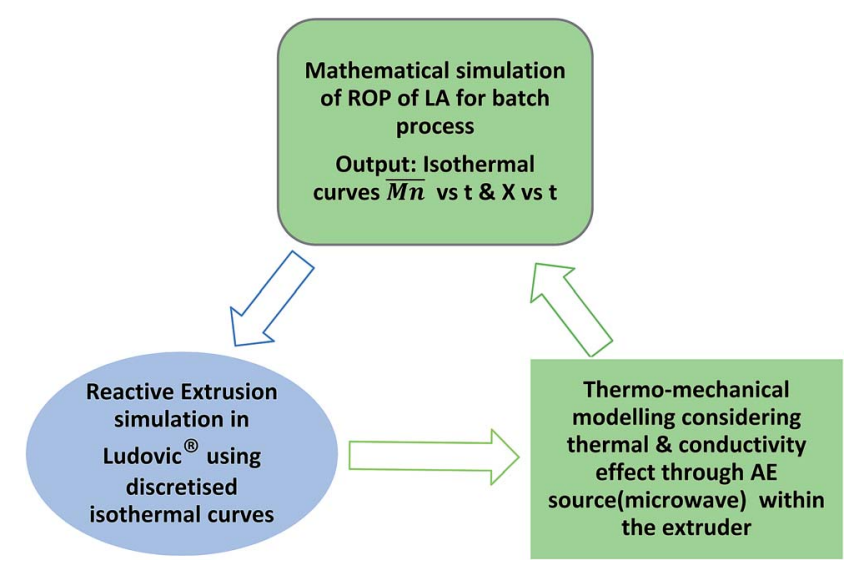

Fig. 5 Input and output for continuous extrusion simulation. outcome over each of the subsections. Details regarding the parameters and modelling method are well defined in one of our previously published work. ${ }^{30}$

A flowchart about the development of the whole simulation process is presented in Fig. 5 .

3.2.1. Mechanism of reactive extrusion through Ludovic ${ }^{\circ}$. Simulation through Ludovic ${ }^{\circ}$ detailed the thermo-mechanical behaviour of twin screw extruders. ${ }^{32}$ It deals with the parameters which directly affect the reaction output such as residence time of mixed material, rate constants, viscosity and thermomechanical flow. Stationary thermo-mechanical flow is computed on the basis of:

Geometrical discretization of the channel zone-C chamber of the screw and material flow of the mixture, as shown in Fig. 6.

Changes in pressure and temperature are computed for discrete volumes. Temperature and pressure both updated from the exit to the upstream part of the screw.

For the sensitivity of temperature effect, Ludovic ${ }^{\circledR}$ provides the temperature at each C-chamber zone Fig. 6 . This temperature is the result of mechanical friction, conduction and alternative energy applied within the extruder. The geometry of the extruder, rotation speed of the screw, throughput and melt influence are factors that affect the mechanical energy from shearing; and this impacts the thermal response of the material.

3.2.2. Alternative energy implementation in Ludovic $\AA$ software. In literature, to the best of the authors' knowledge, application of AE source within Ludovic to obtain the simulation of continuous reactive extrusion has not been reported. The basic principle behind considering AE source in the reaction process is as the source of heat or thermal impact on reaction mechanism. Due to its unique application, the effect of $\mathrm{AE}$ source on reaction is different to those that occur during conventional heating (Heat Furnace). AE source device was installed to the barrel lane (Grey Zone) in Ludovic ${ }^{\circledR}$ Fig. 6. The two specific requirements are

- Hollow cylinder zone (no metal screw, kneading etc.)

- Fully filled zone

To make the application of AE source (microwave) effective, full filled zone is to be designed under the alternative energy input section. Fig. 6 (ref. 32) shows an example of screw configuration setup with AE source barrel (chamber in grey colour).

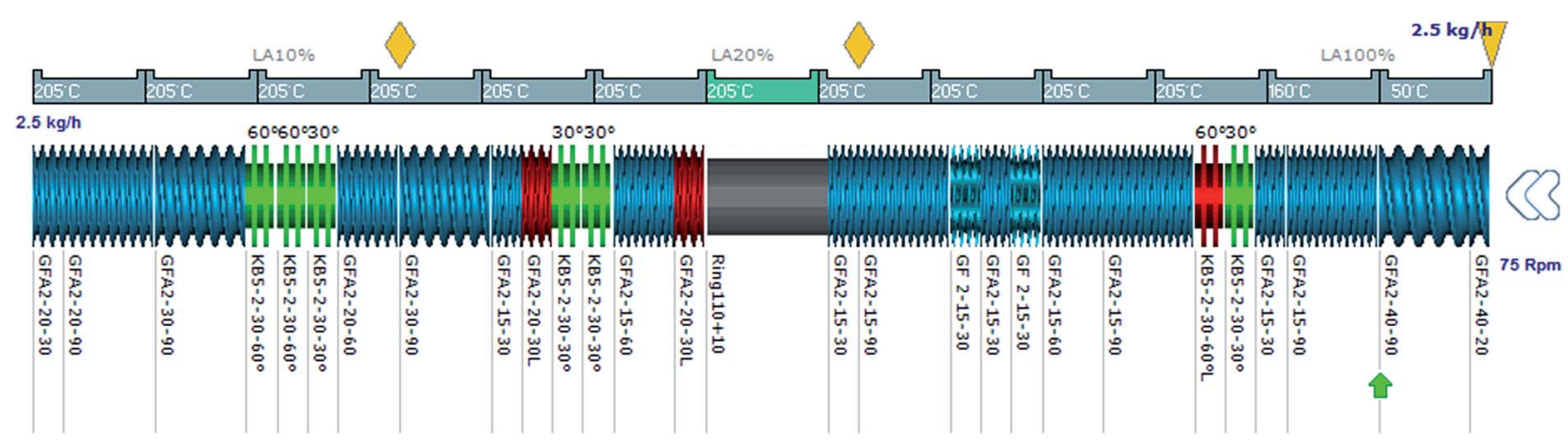

Fig. 6 Screw profile with AE source device. ${ }^{32}$ 
3.2.3. Thermo-mechanical modelling of Ludovic. Consideration of two crucial physical parameters, conductivity and mechanical dissipation, for the thermal balance equation was made. The equation has AE source power as a third term under AE source (microwave) barrel. The updated heat equation is:

$$
\rho \times C_{\mathrm{p}} \times \mathrm{d} T / \mathrm{d} t=W_{\text {dissipation }}+W_{\text {conduction(screw) }}+W_{\mathrm{AE}(\text { microwave) }}
$$

This equation is then computed in each element and Ludovic ${ }^{\circledR}$ provides the variation of temperature due to AE source (Fig. 7) with the associated effects of thermal and conduction. Finally, these three effects are combined in order to finalise the global evolution of temperature within the twin screw extruder. ${ }^{32}$

Fig. 7 shows the contribution of 3 different effects to the variation of temperature. The feeding zone is at the right corner and the mixture flows from right to left side. In fact, in $\mathrm{AE}$ source zone, no barrel regulation is mounted also due to the use of the ring (no screw), the shear effect is negligible and only $\mathrm{AE}$ act as the source of heating.

For the application of the alternative energy in the reaction process, microwave source or Ultrasound Sonification seems to impact the polymerisation reaction system. ${ }^{\mathbf{1 7 - 2 4}}$ The AE power impact is taken into account as a third term (in addition to conduction and dissipation power) in the thermal balance equation. ${ }^{1}$

\section{Results \& discussion}

\subsection{Experimental result}

Data of average residence time (RT), temperature ( $T$ ), the number average molecular weight $\left(\overline{M_{\mathrm{n}}}\right)$, average molecular weight $\left(\overline{M_{\mathrm{w}}}\right)$ and conversion $(X)$ from the reactive extrusion experiments using microwave during reaction process are provided in Table 3 . It was observed that increase in temperature results in an increase in $\overline{M_{\mathrm{n}}}, \overline{M_{\mathrm{w}}}$ and $X$ for the same initial conditions. Also, $\overline{M_{\mathrm{n}}}, \overline{M_{\mathrm{w}}}$ and $X$ increase when microwave (AE) source is applied. For example, in the experiment at $180^{\circ} \mathrm{C}$, the value of conversion was found to be higher $(80 \%)$ when the microwave was applied than in the case without the microwave (62\%). A similar trend of increase in conversion $(X)$ was also observed at $160^{\circ} \mathrm{C}$.

4.1.1. Impact of $\mathrm{AE}$ source on extrusion experiment. Microwave energy can influence different stages of the reaction system depending on the position where it is introduced into the

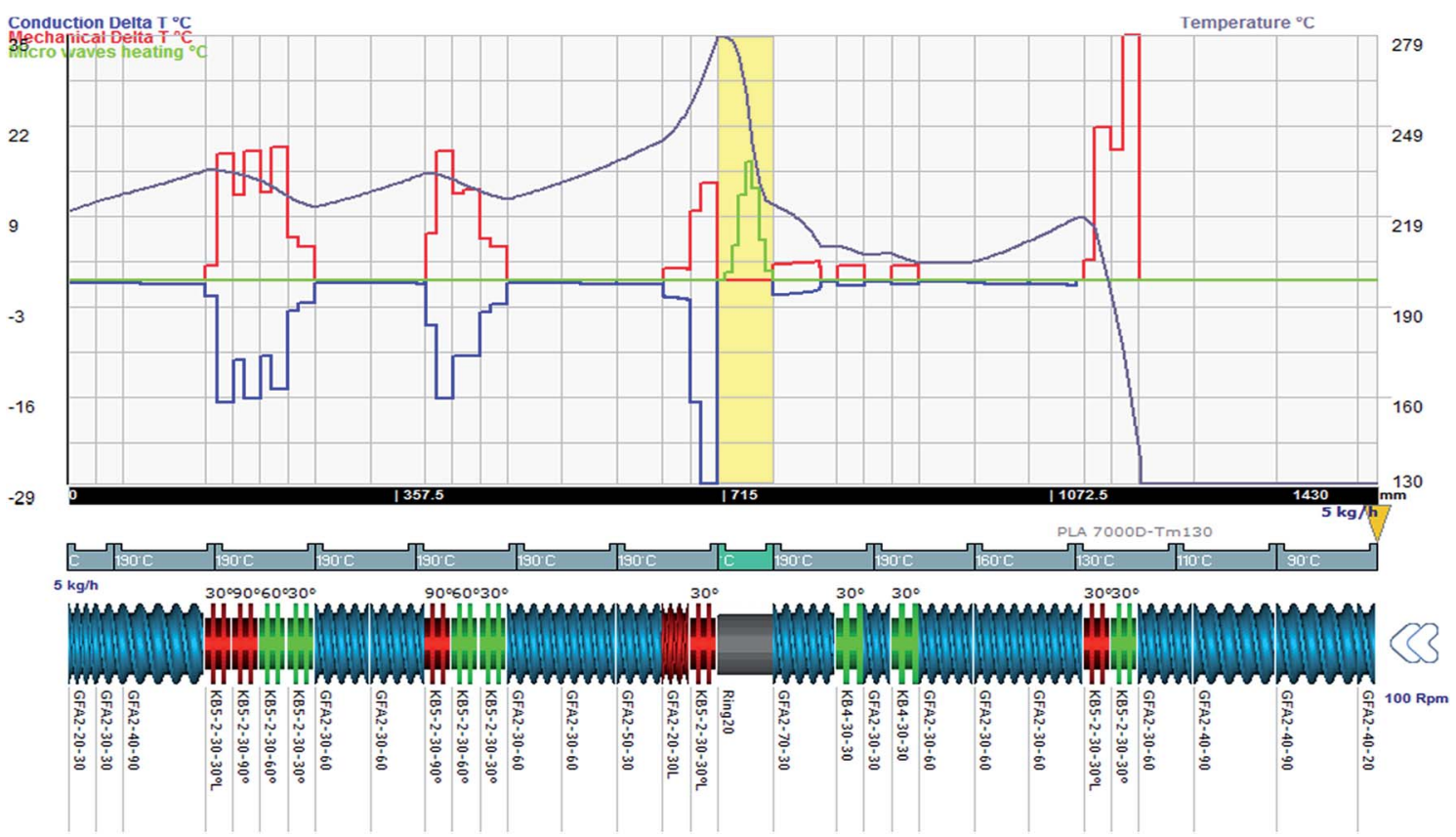

Fig. 7 Temperature variation due to conduction (purple), due to mechanical effect (red) and micro-wave (AE) (100-300 W) (green) effect and result on final temperature (grey).

Table 3 Reactive extrusion experimental data

\begin{tabular}{|c|c|c|c|c|c|c|}
\hline $\mathrm{RT}(\min )$ & $T\left({ }^{\circ} \mathrm{C}\right)$ & Microwave & $\overline{M_{\mathrm{n}}}\left(\mathrm{g} \mathrm{mol}^{-1}\right)$ & $\overline{M_{\mathrm{w}}}\left(\mathrm{g} \mathrm{mol}^{-1}\right)$ & $\mathrm{rpm}$ & $X(\%)$ \\
\hline \multirow[t]{2}{*}{20} & 180 & Yes & 34763 & 50059 & 600 & 80 \\
\hline & & No & 31456 & 44256 & 600 & 62 \\
\hline & & No & 33564 & 50653 & 300 & 70 \\
\hline
\end{tabular}


system. Different effects can be obtained: from mainly preheating the material, when introduced at a too early stage, to efficient heating of a main lactide containing reaction mixture, through to temperature homogenisation and local overheating when placed at very late extrusion stages. When using a matching combination of microwave incorporation position and underlying screw configuration, impressive influence, roughly $M_{\mathrm{n}}(39000) \mathrm{g} \mathrm{mol}^{-1}$ on the reaction can be noted.

The application of microwave energy directly to the polymerisation mixture allowed the temperature to be increased quickly and efficiently, resulting in improved lactide conversion and molecular properties. However, when introduced at high temperatures or at a late reaction stage, the addition of microwave energy can increase the overall temperature excessively that causes backbiting reaction to dominate and resulting in polymer degradation.

\subsection{Results of reactive extrusion simulation (Ludovic ${ }^{\circledR}$ )}

4.2.1. Extrusion simulation without AE source. The simulation of the extrusion process has been performed by taking in account the absence and presence of $\mathrm{AE}$ source in the reaction process.
The area of $\mu$-wave is designed in order to test the effect of such alternative energy Fig. 8. In this section, only results without $\mu$ wave are presented.

Fig. 9 shows the screw design and the evolution of temperature and residence time and the evolution of the kinetics. This kinetics has been introduced within Ludovic with the model presented in Fig. 2 and 3 of our previous work. ${ }^{30}$ Similarly, Fig. 10 shows the variation of $M_{\mathrm{n}}$ and $X$ with time and temperature.

4.2.2. Extrusion simulation with AE source. In order to be able to install the microwave equipment, a similar screw design than the previous one (see Fig. 6), has been designed (the only difference consists in the element after the hollow part replaced by a reverse element in order to ensure a totally filled hollow elements).

In such configuration and for standard operating conditions (300 rpm, $1 \mathrm{~kg} \mathrm{~h}^{-1}$ ), on Fig. 11, the evolution of temperature and residence time are illustrated. The level of power is $250 \mathrm{~W}$. It is noticed that the evolution of temperature in the area of microwave equipment is important but finally it does not exceed $200{ }^{\circ} \mathrm{C}$. The final residence time stays for 430 seconds until the final mixing zone which seems to be useless. On Fig. 12, the evolution of conversion ratio $(X)$ and molecular

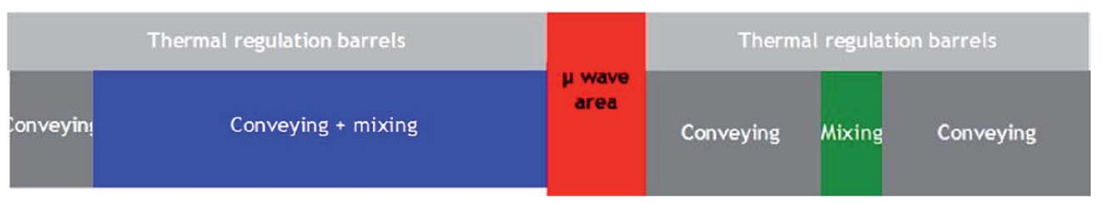

Fig. 8 Screw design and material mixing-Leistritz $18 \mathrm{~mm}$ screw diameter.

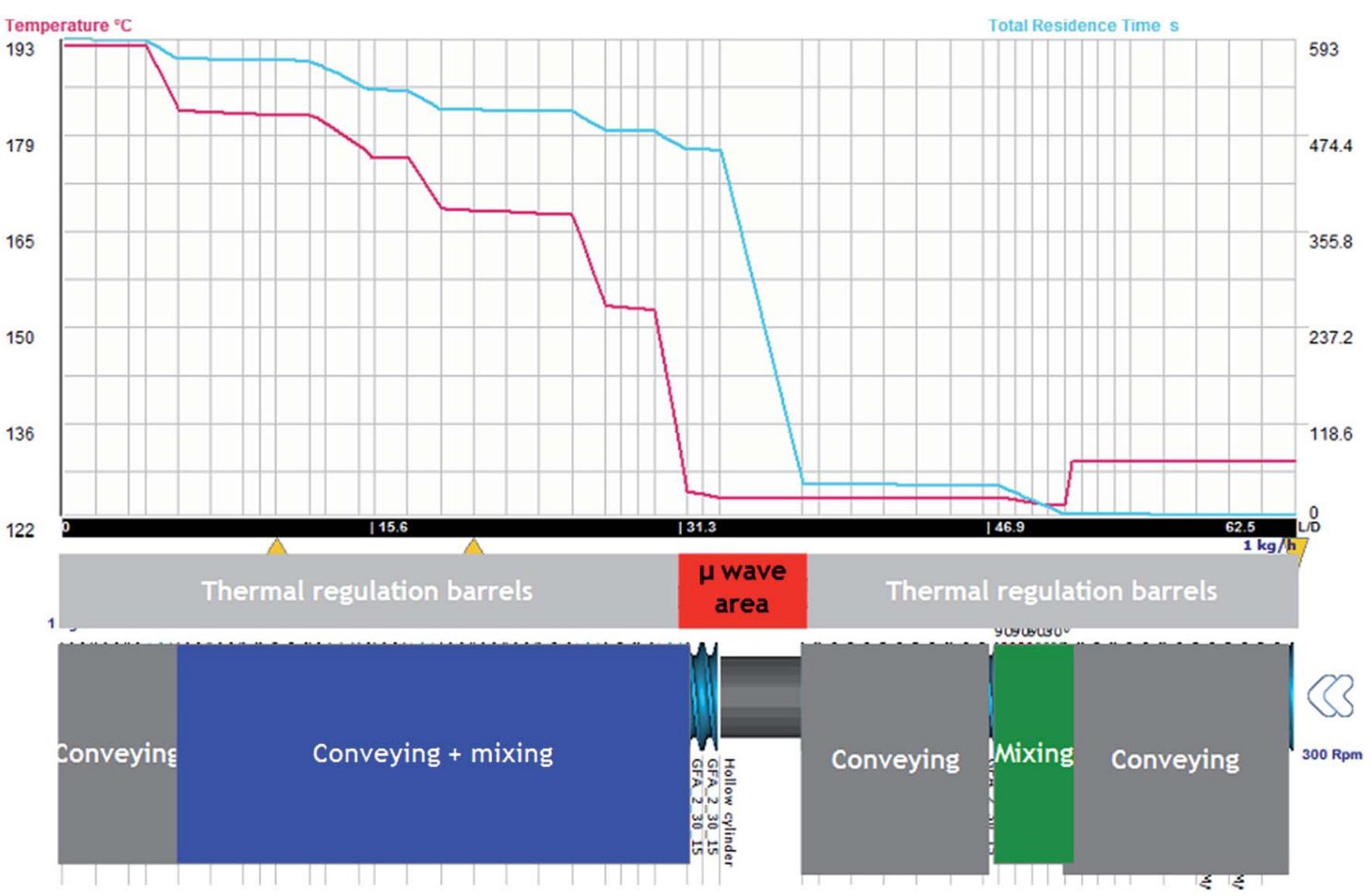

Fig. 9 Evolution of temperature (red) and residence time (blue) in extruder. 


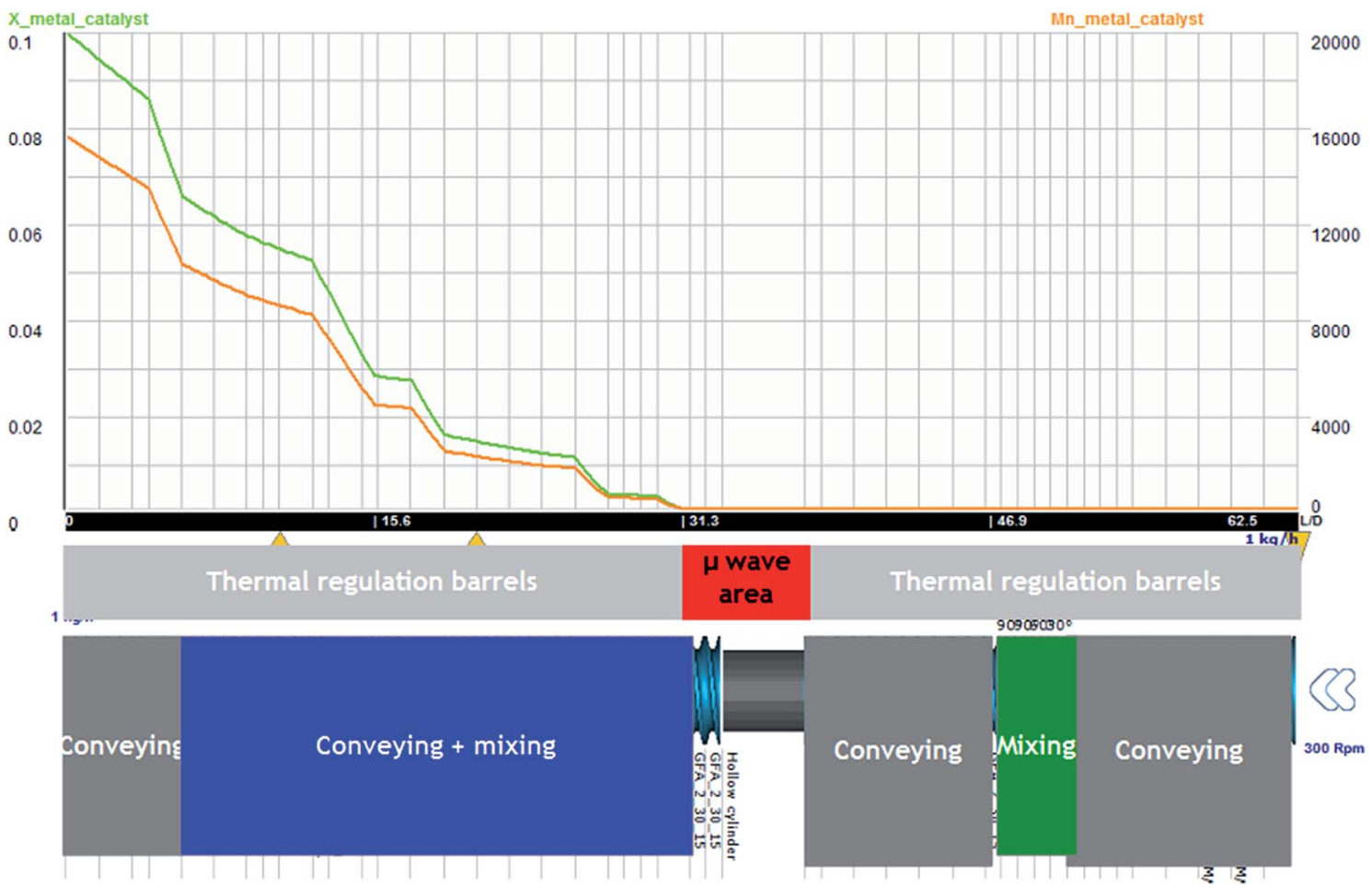

Fig. 10 Evolution of conversion ratio (green) and molecular weight (orange) in extruder.

weight $\left(M_{\mathrm{n}}\right)$, confirm the interest of such equipment which speeds up the reaction.

This analysis is necessary to keep in mind for the support of the scaling up design for the industrial case.
The impact of AE source shows very clear in (Fig. 11 and 12) that microwave energy boost the variation in temperature of the reaction process and total residence time. Similarly, the impact of $\mathrm{AE}$ source influences the variation in $X$ and $M_{\mathrm{n}}$. So the

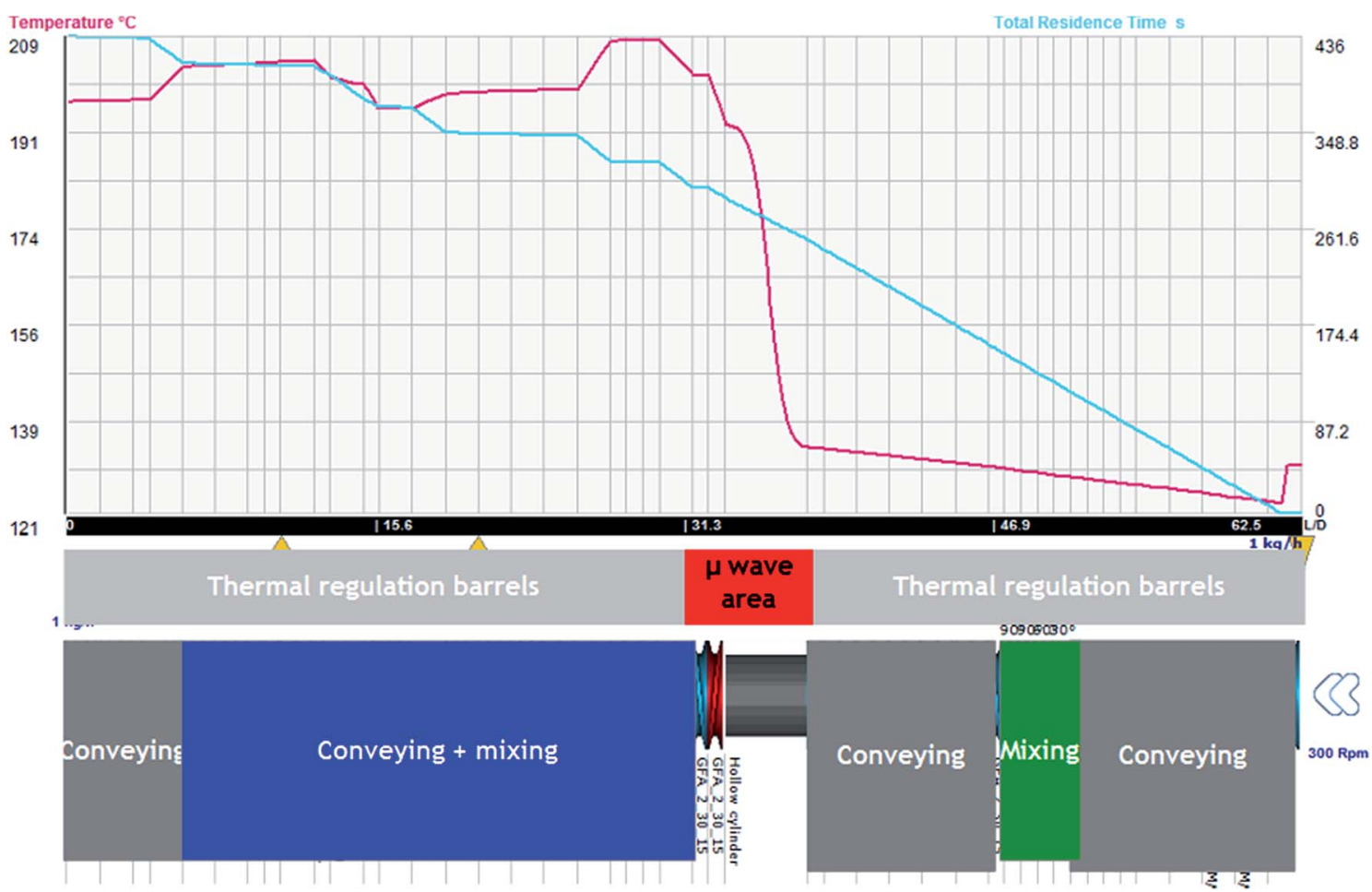

Fig. 11 Evolution of temperature (red) and residence time (blue). 


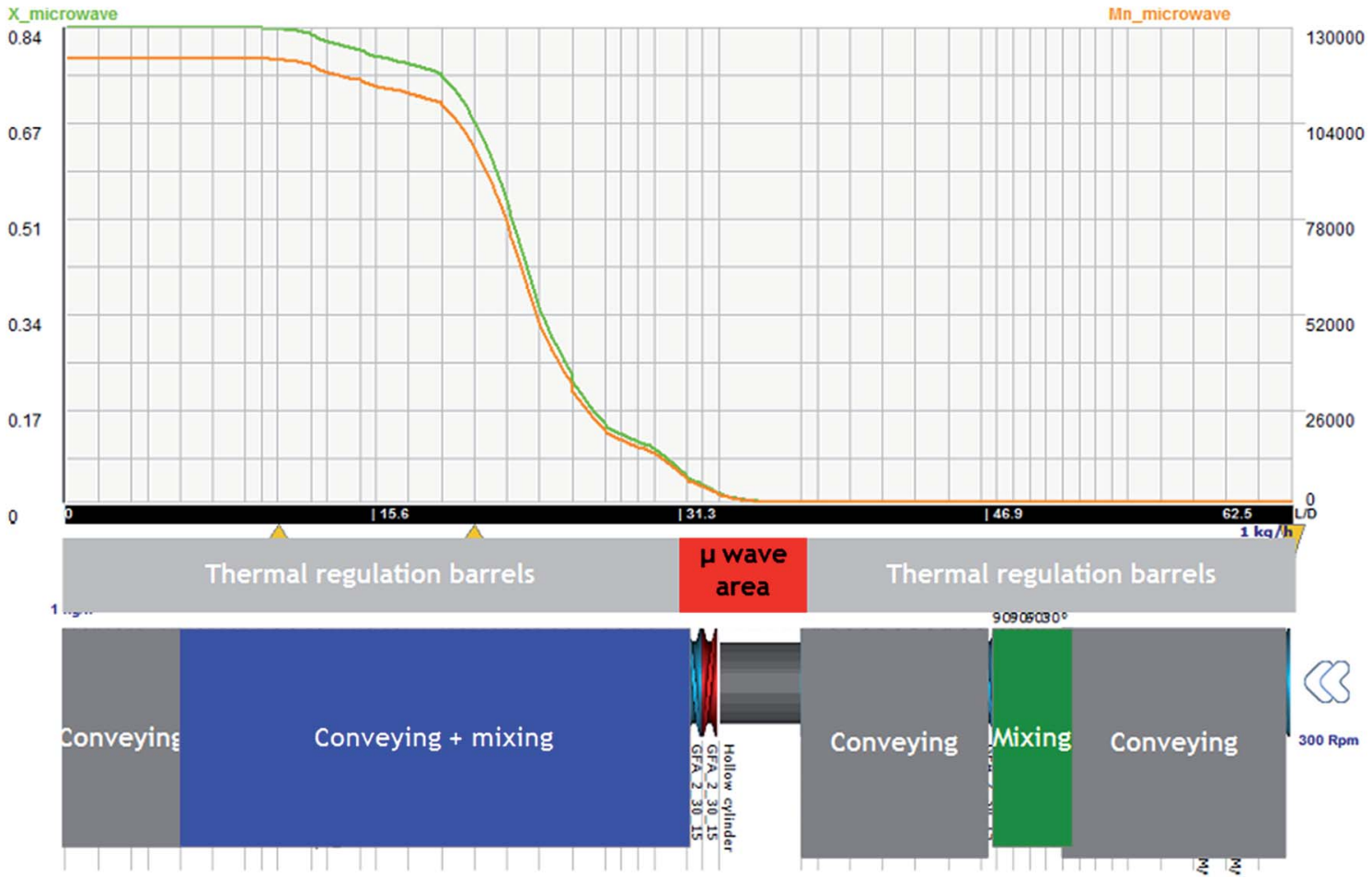

Fig. $12 \overline{M_{\mathrm{n}}}$ (orange) vs. $T$ \& $X$ (green) vs. $T$ obtained with Ludovic $®$ for $T(50-220){ }^{\circ} \mathrm{C}, \mathrm{AE}=250 \mathrm{~W}, 300 \mathrm{rpm}$.

positive impact of $\mathrm{AE}$ source in the extrusion process both in experimental and simulation modelling process has been easily shown.

4.2.3. Comparison of extrusion experiment and Ludovic ${ }^{\circledR}$ simulation results

(a). RTD comparison with throughput and barrel temperature. The performed correlations regarding residence time distribution (RTD) through residual lactide (RL) with rpm and barrel temperature are presented in Fig. 13. For Ludovic, the residual percentage of lactide (\% LA) is represented by 1 conversion ratio. Through comparison, it was found that the residual \% LA is not representative of the evolution of kinetics as the function of time and temperature. For Ludovic simulation, the barrel temperature shows the very limited effect on residence time and temperature. Potentially, this is the reason why the conversion ratio is not sensitive. For extrusion experiment and simulation, the variation of RL seems to be very different in general.

\subsection{Average molecular weight comparison at various temperatures}

Simulation and experimental extrusion process results for the average molecular weight $\left(M_{\mathrm{n}}\right)$ at various temperature shows that, at low temperatures, the $M_{\mathrm{n}}$ value reported through Ludovic ${ }^{\circledR}$ is higher than that for the experiment. This is related to the higher residual lactide (RL) reported through Ludovic ${ }^{\circledR}$ than the experiment (Fig. 13). If RL is high signifies, RT is high, it means the material mixture remains for a long time in the mixing chambers which facilitates the proper polymerization process and produces the high output. Proper mixing of material in the extruder chamber is one of the key features for
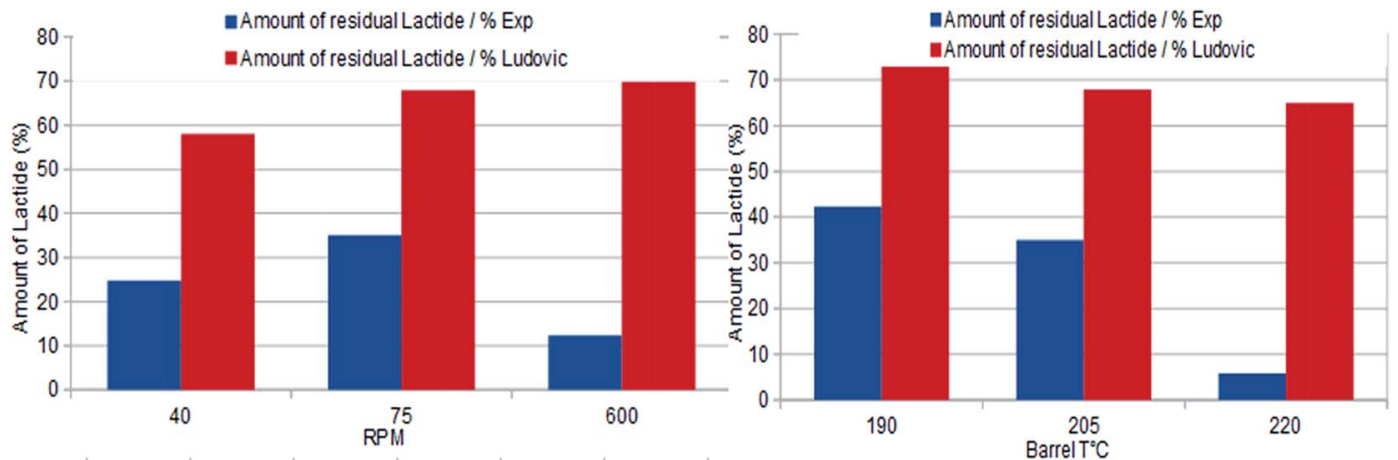

Fig. 13 Correlation of residual lactide according to rpm \& correlation of residual lactide according to barrel temperature. 
Table 4 Comparison between simulation ("Ludovic ${ }^{\circledR}$ ") and experimental results ("Expt.")

\begin{tabular}{llll}
\hline S. no. & $\begin{array}{l}\text { Temp. } \\
\left({ }^{\circ} \mathrm{C}\right)\end{array}$ & $\overline{M_{\mathrm{n}}}($ Expt. $)\left(\mathrm{g} \mathrm{mol}^{-1}\right)$ & $\overline{M_{\mathrm{n}}}($ Ludovic $\AA)$ \\
\hline 1 & 160 & 38681 & 40580 \\
2 & 180 & 34763 & 36456 \\
3 & 200 & 32102 & 34011
\end{tabular}

optimum polymerization. As temperature increases, $M_{\mathrm{n}}$ starts falling down. This can be explained by the activation of side reactions at a thermal threshold, as a result of the heat contribution of the $\mathrm{AE}$ source. The values of $M_{\mathrm{n}}$ through extrusion experiment and Ludovic ${ }^{\circledR}$ has been mentioned in Table 4.

\section{Conclusions}

Reactive extrusion of PLA aided by AE (microwave) source was successfully conducted at Fraunhofer ICT lab and based on initial reaction data. Simulation of reaction mechanism has been conducted to further provide input for modified Ludovic ${ }^{\circledR}$ software and validate both experimental and simulation outputs. This implementation poses a step forward in the stateof-the-art of ROP of lactide both technically and analytically. The use of $\mathrm{AE}$ source has a positive impact on the reaction process as reported above both experimentally and through theoretical simulation. The application of the AE source shows the boost in RT and in the result, higher $M_{\mathrm{n}}$ values. In general microwave energy, as a source of heat facilitated the polymerization process up to a certain temperature range (160-180) ${ }^{\circ} \mathrm{C}$. At higher temperatures, the effect of the microwaves was observed not very promising as it can trigger side reactions that degrade the PLA chain. The implementation of AE sources (microwave or ultrasound) for PLA production can be chosen based on the experimental setup (temperature range) and application. Overall, the impact of AE source is proven to be positive for the reactive extrusion process for PLA formation. Further investigation will be made based on new experimental trials considering the more wide range of temperature and the new class of eco-friendly catalyst and co-catalyst combinations.

\section{Acknowledgements}

The Authors would like to thank the European Commission for their financial support (FP7 InnoREX project grant number: 309802). The authors would also like to acknowledge MUEGGE, Germany, SCC France, Fraunhofer-ICT and other partners from http://www.InnoREX.eu consortium for providing support.

\section{References}

1 S. Jacobsen, H.-G. Fritz, P. Degée, P. Dubois and R. Jérôme, Continuous reactive extrusion polymerisation of L-lactide an engineering view, Macromol. Symp., 2000, 153(1), 261273.
2 D. L. Kaplan, Introduction to biopolymers from renewable resources, in Biopolymers from Renewable Resources [Internet], ed. D. D. L. Kaplan, Springer, Berlin Heidelberg, 1998, pp. 1-29, cited April 2 2014, Macromolecular Systems - Materials Approach, available from, http:// link.springer.com/chapter/10.1007/978-3-662-03680-8_1.

3 K. Madhavan Nampoothiri, N. R. Nair and R. P. John, An overview of the recent developments in polylactide (PLA) research, Bioresour. Technol., 2010, 101(22), 8493-8501.

4 N. A. J. Platzer and American Chemical Society, Division of Industrial and Engineering Chemistry, American Chemical Society, Division of Polymer Chemistry. Polymerization kinetics and technology [Internet], American Chemical Society, Washington, 1973, cited September 26 2013, available from, DOI: 10.1021/ba-1973-0128.

5 PlasticsEurope-Plastics - the Facts 2013 [Internet], cited August 12 2014, available from, http://www.plasticseurope.org/ Document/plastics-the-facts-2013.aspx?FolID $=2$.

6 S. Inkinen, M. Hakkarainen, A. C. Albertsson and A. Södergård, From lactic acid to poly(lactic acid) (PLA): characterization and analysis of PLA and its precursors, Biomacromolecules, 2011, 12(3), 523-532.

7 S. S. Ray and M. Okamoto, Biodegradable polylactide and its nanocomposites: opening a new dimension for plastics and composites, Macromol. Rapid Commun., 2003, 24(14), 815840.

8 P. Dubois, C. Jacobs, R. Jerome and P. Teyssie, Macromolecular engineering of polylactones and polylactides. 4. Mechanism and kinetics of lactide homopolymerization by aluminum isopropoxide, Macromolecules, 1991, 24(9), 2266-2270.

9 D. R. Witzke, R. Narayan and J. J. Kolstad, Reversible kinetics and thermodynamics of the homopolymerization of L-lactide with 2-ethylhexanoic acid tin(II) salt, Macromolecules, 1997, 30(23), 7075-7085.

10 J. Char, E. Brulé, P. C. Gros, M. N. Rager, V. Guérineau and C. M. Thomas, Synthesis of heterotactic PLA from raclactide using hetero-bimetallic $\mathrm{Mg} / \mathrm{Zn}-\mathrm{Li}$ systems, $J$. Organomet. Chem., 2015, 796, 47-52.

11 W. Amass, A. Amass and B. Tighe, A review of biodegradable polymers: uses, current developments in the synthesis and characterization of biodegradable polyesters, blends of biodegradable polymers and recent advances in biodegradation studies, Polym. Int., 1998, 47(2), 89-144.

12 N. E. Kamber, W. Jeong, R. M. Waymouth, R. C. Pratt, B. G. G. Lohmeijer and J. L. Hedrick, Organocatalytic ringopening polymerization, Chem. Rev., 2007, 107(12), 58135840.

13 E. T. H. Vink, K. R. Rábago, D. A. Glassner and P. R. Gruber, Applications of life cycle assessment to NatureWorksTM polylactide (PLA) production, Polym. Degrad. Stab., 2003, 80(3), 403-419.

14 P. Degee, P. Dubois, C. Jacobs, R. Jerome and H. G. Fritz, Macromolecular engineering of polylactones and polylactides. 4. New catalysis for fast bulk ring-opening polymerization of lactide monomers, Macromol. Symp., 1999, 144, 289-302. 
15 I. Başaran and A. Oral, Synthesis and characterization of poly(L-lactic acid)/clay nanocomposite via metal-free process, Polym.-Plast. Technol. Eng., 2013, 52(12), 1271-1276.

16 L. Mespouille, O. Coulembier, M. Kawalec, A. P. Dove and P. Dubois, Implementation of metal-free ring-opening polymerization in the preparation of aliphatic polycarbonate materials, Prog. Polym. Sci., 2014, 39(6), 1144-1164.

17 L. Zong, S. Zhou, N. Sgriccia, M. C. Hawley and L. C. Kempel, A review of microwave-assisted polymer chemistry (MAPC), J. Microwave Power, 2003, 38(1), 49-74.

18 P. Albert, H. Warth, R. Mülhaupt and R. Janda, Comparison of thermal and microwave-activated polymerization of $\varepsilon$ caprolactone with titanium tetrabutylate as catalyst, Macromol. Chem. Phys., 1996, 197(5), 1633-1641.

19 L. J. Liu, C. Zhang, L. Q. Liao, X. L. Wang and R. X. Zhuo, Microwave-assisted polymerization of D,L-lactide with stannous octanoate as catalyst, Chin. Chem. Lett., 2001, 12(8), 663-664.

20 Z. Cheng, X. Zhu, N. Zhou, J. Zhu and Z. Zhang, Atom transfer radical polymerization of styrene under pulsed microwave irradiation, Radiat. Phys. Chem., 2005, 72(6), 695-701.

21 F. Wiesbrock, R. Hoogenboom and U. S. Schubert, Microwave-assisted polymer synthesis: state-of-the-art and future perspectives, Macromol. Rapid Commun., 2004, 25(20), 1739-1764.

22 S. Jing, W. Peng, Z. Tong and Z. Baoxiu, Microwaveirradiated ring-opening polymerization of $\mathrm{D}, \mathrm{L}$-lactide under atmosphere, J. Appl. Polym. Sci., 2006, 100(3), 2244-2247.

23 M. Frediani, D. Sémeril, D. Matt, F. Rizzolo, A. M. Papini, P. Frediani, L. Rosi, M. Santella and G. Giachi, L-Lactide polymerization by calix[4]arene-titanium(Iv) complex using conventional heating and microwave irradiation, e-Polym., 2010, 19, 1-8.

24 G. Giachi, M. Frediani, L. Rosi and P. Frediani, Synthesis and processing of biodegradable and bio-based polymers by microwave irradiation, in Microwave heating, ed. U. Chandra, InTech, June 2011, pp. 181-206.

25 M. Vukomanović, M. Mitrić, S. D. Škapin, E. Žagar, J. Plavec, N. Ignjatović, et al., Influence of ultrasonic processing on the macromolecular properties of poly(D,L-lactide-co-glycolide) alone and in its biocomposite with hydroxyapatite, Ultrason. Sonochem., 2010, 17(5), 902-908.

26 M. Jevtić, A. Radulović, N. Ignjatović, M. Mitrić and D. Uskoković, Controlled assembly of poly(D,L-lactide-coglycolide)/hydroxyapatite core-shell nanospheres under ultrasonic irradiation, Acta Biomater., 2009, 5(1), 208-218.

27 G. J. Price, E. J. Lenz and C. W. G. Ansell, The effect of highintensity ultrasound on the ring-opening polymerisation of cyclic lactones, Eur. Polym. J., 2002, 38(9), 1753-1760.

28 InnoREX. [Online], available: http://www.innorex.eu/ about.php.

29 S. P. Dubey, H. A. Abhyankar, V. Marchante, J. L. Brighton and B. Bergmann, Mathematical modeling for continuous reactive extrusion of poly lactic acid formation by ring opening polymerization considering metal/organic catalyst and alternative energies, World Acad. Sci. Eng. Technol., $2015,9(2)$.

30 S. P. Dubey, H. A. Abhyankar, V. Marchante, J. L. Brighton, K. Blackburn, C. Temple, B. Bergmann, G. Trinh and C. David, Modelling and validation of synthesis of poly lactic acid using an alternative energy source through a continuous reactive extrusion process, Polymers, 2016, 8(4), 164.

31 Compounding and extrusion-Fraunhofer ICT, http:// www.ict.fraunhofer.de/en/comp/pe/ce.html.

32 Ludovic-Twin screw extrusion-SCConsultants [Internet], cited 2014 November 19, available from: http://www.scconsultants.com/ en/ludovic-twin-screw-simulation-software.html.

33 S. P. Dubey, H. A. Abhyankar, V. Marchante, J. L. Brighton and K. Blackburn, Chronological review of the catalytic progress of polylactic acid formation through ring opening polymerization, Int. Res. J. Pure Appl. Chem., 2016, 12(3), 120.

34 J.-P. Puaux, I. Banu, I. Nagy and G. Bozga, A study of L-lactide ring-opening polymerization kinetics, Macromol. Symp., 2007, 259(1), 318-326.

35 I. Banu, J.-P. Puaux, G. Bozga and I. Nagy, Modeling of Llactide polymerization by reactive extrusion, Macromol. Symp., 2010, 289(1), 108-118. 